\title{
Integrating Project Based Learning Components into Woodwork Technology Education Curriculum at Colleges of Education in Nigeria
}

\author{
Muhammad Umar Isa ${ }^{1, *}$, Yusri Bin Kamin', Umar Lawal ${ }^{2}$ \\ ${ }^{1}$ Department of Technical and Engineering Education, School of Education, Faculty of Social Sciences and Humanities, Universiti \\ Teknologi, Malaysia (UTM), Malaysia \\ ${ }^{2}$ Department of Woodwork Technology Education, School of Secondary Education (Technical), Federal College of Education (Technical) \\ Bichi, Nigeria
}

Received January 22, 2020; Revised April 1, 2020; Accepted April 21, 2020

Copyright $\odot 2020$ by authors, all rights reserved. Authors agree that this article remains permanently open access under the terms of the Creative Commons Attribution License 4.0 International License

\begin{abstract}
The main aim of this paper is to investigate project-based learning components suitable for integration into woodwork technology education curriculum (WTE) at Colleges of education (COE) in Nigeria. The study employed an intrinsic case study design. The population for the study comprised 12 respondents involving woodwork technology education lecturers and curriculum planners in north western Nigeria. Semi structured Interview protocol was the instrument used for collecting data for the study, while NVIVO 12 was used to analyse the qualitative data. Findings from the study revealed that the curriculum structure of WTE at COE does not include PoBL. The findings also revealed $21^{\text {st }}$ century skills, inquiry and innovation, publicly presented product among the PoBL components suitable for integration into WTE curriculum at $\mathrm{COE}$ in Nigeria. Findings also revealed relevance of integrating PoBL in WTE curriculum, and equally showed from the responses of the participants that involvement of WTE students in investigation, collaboration grouping, and provision of adequate resource facilities as ways through which PoBL components can enhance student skill when integrated into WTE curriculum. Therefore, integrating components of PoBL into WTE curriculum affords students' the opportunity to enhance their skills in WTE, and bridge the skill gap existing between WTE graduates and the industries.
\end{abstract}

Keywords Project Based Learning, Woodwork Technology Education, Colleges of Education, Curriculum, Components of Project Based Learning, $21^{\text {st }}$ Century Skills

\section{Introduction}

Project based learning (PoBL)) is a student driven teacher facilitated instruction. It is an active learning used in the $21^{\text {st }}$ century for skills and knowledge transmission. Essentially, PoBL as a student-centred learning is useful in learning skills in various courses for achieving $21^{\text {st }}$ century competences [1]. This is why PoBL has been recognised as an instructional model that centres around projects which engages students in learning knowledge and skills through an extended inquiry process structured around complex, authentic (real-life) questions and carefully designed products and tasks [2]. However, to achieve a meaningful PoBL in any educational setting, components of PoBL must be made part of the curriculum in order to fulfil its educational objectives [3]. In this regard an educational course like woodwork technology education that emphasises skill acquisition requires PoBL integration in its curriculum.

Woodwork Technology Education (WTE) is a course of study in Technical and Vocational education and Training (TVET) program at Colleges of Education (COE) in Nigeria designed to promote the acquisition of skills and competencies in woodworking in order to enable individuals to become productive and contribute to national economic growth [4]. Accordingly, [5] described WTE as a course offered in COE aimed towards preparing students for gainful employment in the world of work. Further, due to the rapid changes in technology, WTE students need to be equipped with the competencies needed to cope in modern workforce. For this reason, there is every need for tertiary institutions like COE offering WTE as a course to restructure its curriculum towards accommodating changes in work place so as to produce 
WTE graduates who can fit in today's $21^{\text {st }}$ century work-based economy and society [5]. Additionally, these changes in curriculum must also accommodate effective instructional approaches like PoBL which guarantees enhancement of student $21^{\text {st }}$ century skills and competences.

Building on the above, integrating PoBL components in WTE curriculum becomes desirable because of the immense role PoBL plays in enhancing student skills and competency. Therefore, there is a need to explore PoBL in WTE with a view to determining essential components of PoBL suitable for integration into WTE at COE in Nigeria aimed towards improving instructional processes in WTE for efficiency in student skill acquisition.

\section{Problem Background}

Colleges of education are tertiary institutions in Nigeria that provide TVET beyond secondary school level. TVET programmes at colleges of Education are developed in such a way that it helps the learners to acquire knowledge, skills, values and attitudes that promote self-reliance [6]. Additionally, the philosophy of TVET program in colleges of education as stipulated in the National Certificate in education (NCE) minimum standard for vocational and technical education is to provide TVET (WTE) students with the intellectual and professional background adequate for teaching technical subjects and to make them adaptable to changing situation in technological development not only in the country, but also in the world at large [7]. The NCE minimum standard further stipulated the following as the main objectives of TVET program in COE in which WTE inclusive:

- To produce qualified technical teachers and practitioners of teaching capable of teaching basic technology in the junior secondary schools

- To produce Technical NCE teachers who will be able to inculcate scientific technological attitudes and values into the society

- To produce qualified technical teachers motivated to start the so much desired revolution of technological development from the Nigerian schools.

In pursuant of the above stated objective, the [8] in its national policy on education (NPE) stated that in order to realize the goals of education in Nigeria and gain from its contribution to national economy, tertiary education institutions shall pursue the goals of education through quality teaching and learning by the provision of a more practical based curriculum that is learner centred and relevant to the needs of the labour market. However, a cursory look into the NCE minimum standard curriculum used for WTE shows contradiction to the NPE for not including the learner centred instructional approach in the curriculum of WTE. This indicates a gap in the curriculum that needs to be filled. WTE curriculum in Nigeria COE focuses on a teacher centred approach of instruction without emphasis on $21^{\text {st }}$ century skills and competencies [9]. To this effect, WTE students graduate from colleges without the relevant employability skills needed in the $21^{\text {st }}$ century labour market. Ideally, WTE curricular is supposed to prepare students with $21^{\text {st }}$ century skills to face challenges in the world of work. For this reason, integrating PoBL components into WTE curriculum becomes inevitable in view of the role PoBL plays in enhancing student employability skills.

In Nigeria, there has been persistent report about the inefficiency of WTE graduates in the practice of their field. In this regard, [10] attributed the lack of skills by WTE graduates to the curriculum structure and instructional strategy adopted in WTE. Hence, this study used the perception of WTE stakeholders in determining the components of PoBL suitable for integration in WTE curriculum at $\mathrm{COE}$ with the aim of improving instruction for the enhancement of WTE students $21^{\text {st }}$ century skills for effective employability.

\section{Problem Statement}

Woodwork technology education has continued to impact positively in our daily lives. This is due to the rapid technological development in the wood world of work. The woodwork construction industries have improved over the years due to demand of employers on employees with $21^{\text {st }}$ century skills such as collaboration, creativity, communication and leadership skills. However, the curriculum of WTE at COE in Nigeria seems inadequate for preparing WTE students with the requisite work skill demand for the $21^{\text {st }}$ century. The curriculum of WTE relies more on a teacher centred approach instructions which does not provide opportunity for students to be actively engage in their learning in order to be equipped with $21^{\text {st }}$ century skills. More so, the continued adoption of teacher centred approach like lecture and demonstration method of instruction have resulted to producing WTE graduates without the needed employability skills. Hence, WTE students end up unemployed after graduation from COE.

However, the aforementioned problem will continue to ravage WTE in Nigerian COE unless the curriculum is refocused to adopting a learner centred approach like the PoBL in its instructional approach for imparting knowledge and skill to students. To this end, integrating PoBL components into WTE curriculum could be seen as an approach to improve instructions in WTE and enhance student's $21^{\text {st }}$ century skills for employability.

\section{Project Based Learning Components}

Project based learning is an instructional approach that integrate $21^{\text {st }}$ century skills to prepare students to be 
productive and gainfully employed. Essentially PoBL is described as a tool used to prepare students to meet the $21^{\text {st }}$ century work skill demand and succeed on employment [3]. Accordingly, [11] asserted that PoBL is designed to prepare students for $21^{\text {st }}$ century skills (critical thinking, communication, collaboration, problem solving) that will help students to be successful after graduating from college. This now explains why PoBL is described as a learning approach that centres on projects which engage students in constructive investigations on real world issues that culminate into a final product or public presentation. PoBL is all about connecting students to learning skills through engagement with activities that expose them to problems that help enhance their critical thinking, collaboration and effective communication skills [12]. Similarly, [13] stated that students who learned through PoBL are more engaged in real world problems solving and are able to guide their learning through hands on experience and also exhibit some proficiency of $21^{\text {st }}$ century skills.

Achieving effectiveness in PoBL implementation entails an integration of the components of the PoBL into the curriculum of a program. In this regard, [14] stated that a PoBL curriculum should incorporate components of PoBL so as to create authentic learning processes, experiences and projects. Further, through the integration of PoBL components into a program curriculum, instructors are able to embed content standards and engage students in creative and innovative experiences with the possibility for enhancing student's $21^{\text {st }}$ century skills [15]. PoBL components are therefore, seen as essential elements for successful PoBL implementation. To this effect, some PoBL components are briefly explained here. The Buck Institute for Education (BIE) is the main organ that has devoted its efforts to promoting PoBL globally. The BIE recognized "in-depth inquiry," "driving question," "need to know," "voice and choice," "revision and reflection" and "public audience" all surrounding "significant content" and " $21^{\text {st }}$ Century competences" as their key components to project-based learning.

Building on the above, significant content as an essential component of PoBL entails linking curriculum to reflect essential contents which should have much value to student's interest [3]. Project has to align with the curriculum of a program or course, and has to focus on important knowledge and skills pertaining to specific concepts in the curriculum [16]. This signifies that through significant content student see the connections between the curriculum and real world. Similarly, [17] opined that driving question is a key component in PoBL which guides students in their part of inquiry in exploration of intriguing investigations. Driving question in essence gives students a sense of purpose and challenge, clarifying some of the expected outcomes of the investigation students are carrying out. A good driving question according to [18] captures the heart of the project in clear, convincing language, which gives students a sense of determination. He
(Cervantes) further stated that, the questions should be challenging, open-ended, complex, and linked to the core of what students are expected to learn. Further, a Need to know as an essential component of PoBL direct student to understand the importance of knowledge, understanding concepts and application of skills for problem solving and developing projects [16]. Need to know usually introduce the project with information and intrigues through launching of a project that engages student interest and initiates question and curiosity [18]. This gives the students the zeal to wanting to be inquisitive and interested to learn.

Furthermore, [3] listed inquiry and innovation as the essential component of PoBL which seek to engage student in extended rigorous investigation and utilization of resources to develop solutions that promote the ability of questioning and reasoning. Inquiry leads to innovations with a new answer to driving question, a new solution to a problem or a new product [18]. To this effect, engagement of students with activities that will enhance their innovation skills through rigorous inquiry is crucial. Moreover, considering the value of student ownership in learning, voice and choice as a component of PoBL makes learning more meaningful to students [19]. The idea behind voice and choice as a component of PoBL is allowing students to decide on the content of their learning. According to [20], students feel intrinsically motivated when they take responsibility and ownership of their learning. This explains why in PoBL students take ownership of learning while the teacher serves as a facilitator providing scaffolding guidance.

Furthermore, $21^{\text {st }}$ century skill as a component of PoBL are a set of abilities that students need to develop in order to succeed in global economy [21]. Skills that are needed in the workplace environment are the same skills student need in PoBL experience to be successful at school [22]. This explains why PoBL provides opportunity for students to build skills such as communication, collaboration, critical thinking and the use of technology [23]. In this regard, building $21^{\text {st }}$ century skills in students through PoBL helps to develop their skills and abilities for successful work place career. Feedback and revision in the course of learning makes learning meaningful because it emphasizes that creating high quality products and performances is an important purpose and goal [18]. Publicly presented product entails student presenting their work to a public audience beyond class mates [14]. Public presentation of product gives students a greater sense of ownership and make students feel motivated to learning.

\section{Research Objective}

The main objective of this study is to investigate the perception of stakeholders on the elements of the essential components of PoBL suitable for integration into WTE curriculum at colleges of education in Nigeria 


\section{Research Question}

What are the perceptions of stake holders on the elements of project based learning essential components suitable for integration into WTE curriculum at colleges of education in Nigeria?

\section{Methodology}

Methodology describes the procedures involve in carrying out a study. In this regard, the methodology used for this study is described under the following sub headings:

\subsection{Research Design}

An intrinsic case study design was employed for the study. Intrinsic case study is a type of qualitative study undertaken when the case is unique or is of interest in collecting evidence for the purpose of the study [24]. Additionally, [25] stated that researchers employ intrinsic case study design when studying about events, programs or activities. Similarly, [26] proclaimed that intrinsic case study is best employed when studying about instructional approaches. This explains why this study utilized intrinsic case study as its research design. On this basis, [27] asserted that intrinsic case study is exploratory in nature and preparation about whom to talk with, where to collect data and which events to observe are indispensable.

\subsection{Study Area}

The study was conducted in the north western zone of Nigeria involving Federal college of education Technical Bichi, Kano state, Federal College of education Technical Gusau, Zamfara state, and National commission for colleges of education (NCCE). The reason for selecting the two FCE (T) was because they are different from other conventional colleges of education and because they were specifically established to run TVET programs and to prepare students on dual competency, hat is prospective teachers to impart TVET (WTE) knowledge and skills to secondary /primary school pupils and work in the industry as well. On the other hand, the NCCE was chosen because it is the organisation responsible for curriculum planning and development, monitoring, supervision and accrediting courses for colleges of education in Nigeria.

\subsection{Sample and Sampling Technique}

Purposive sampling was employed in selecting the sampled population for the study. Purposive sampling also called judgemental sampling is the deliberate selection of participants because of the qualities they possessed [28]. Purposive sampling is a sampling technique used in qualitative study to identify and select information rich cases for the proper utilization of available resources involving individuals or group of individuals that are proficient and well informed about a phenomena of interest [29]. In this regard, the sampled population in this study comprised 12 participants involving 6 WTE Senior lecturers from FCE (T) with a master degree or above and 15year experience of lecturing, and 6 WTE curriculum planners from NCCE, making a total of 12 participants used as respondents for the study. The reason for selecting these categories of respondents for this study was because WTE lecturers have several years of experiences in imparting WTE knowledge and skills to students, and the curriculum planners have several years of experiences about WTE curriculum planning and development. Table 1 shows the sampled population for the study.

Table 1. Sampled population for the study

\begin{tabular}{lcc}
\hline \multicolumn{1}{c}{ College/NCCE } & $\begin{array}{c}\text { No of } \\
\text { WTE } \\
\text { Lecturers }\end{array}$ & $\begin{array}{c}\text { No of WTE } \\
\text { Curriculum } \\
\text { Planners }\end{array}$ \\
\hline 1- FCET Bichi, Kano state & 3 & - \\
\hline 2- FCET Gusau, Zamfara state & 3 & - \\
\hline 3- NCCE & & 6 \\
\hline Total & 6 & 6 \\
\hline Grand Total = 12 & &
\end{tabular}

\subsection{Instrumentation}

The instrument used in collecting data for his study was semi structured interview protocol. Semi structured interview is a flexible and powerful instrument used in qualitative study to capture voices and the way people make meanings of their experiences about a particular phenomenon under study [30]. the reason for using semi structured interview is because it gives the respondents the free will to express their views or experiences on the content of the situation under study [31]. Interview protocol was developed based on the specific objective of the study using open ended questions to answer research question that guided the study in order to obtain sufficient information on the components of PoBL suitable for integration into WTE curriculum at COE in Nigeria. Further, in order to obtain the credibility of the interview protocol, the instrument was subjected to validity and reliability checks. In this regard, both content and face validation of the interview protocol was done by experts which included 1 WTE senior lecturer and 1 WTE curriculum planner. The validates were given the interview protocol to make observations and suggestions on the suitability of the structure and question contents in relation to the objective and research question for this study. The final draft of interview protocol was done based on the observations and suggestions made by the validates.

Equally, member check and peer debriefing were used to 
ascertain the trustworthiness of the interview protocol. Member check involves giving the transcript of the interview to the participants for verification to ascertain accurate reporting of their responses [32]. In this study WTE lecturers and curriculum planners were given the transcript of the interview to verify accuracy reporting of their presentation. On the other hand, pear debriefing entails a process where a researcher calls upon a disinterested peer not involved in the research to aid in probing the researcher's thinking about the procedure used to arrive at the outcome of the interview and analysis in order to improve the result [33]. In this study, the interview transcript was given to a qualitative research expert who probed the interpretations and provided additional or alternative interpretations in order to improve the trustworthiness of the result.

The results obtained from the interview session were analysed and interpreted through thematic content analysis using NVIVO version 12 . The data were also translated into a bar chart to show the percentage of respondents' level of acceptability.

\section{Findings}

Findings from the interview on the perception of WTE stake holders on the components of PoBL suitable for integration into WTE curriculum are presented in table 2. Stake holders here are WTE lecturers and curriculum planners. Sample of extracts from the interview are presented in table 2 using the following codes for representation: $\mathrm{RC}=\mathrm{WTE}$ curriculum planner as respondent, $\mathrm{RL}=\mathrm{WTE}$ Senior Lecturer as respondent, P1=Project work, P2 =Project based Learning, P3= PoBL Relevance in Curriculum, P4= Enhancement of Students' Skill, C1=Curriculum contenet, $\mathrm{C} 2=$ Driving question, $\mathrm{C} 3=$ Need to Know $=\mathrm{C} 4=$ Inquiry and Innovation, $\mathrm{C} 5=$ Voice and Choice, $\mathrm{C} 6=21^{\text {st }}$ Century Skills, C7 = Feedback and Revision C8= Public product Presentation.

Table 2. Extracts from Interview

\begin{tabular}{ccc}
\hline Question & Responses & Theme \\
\hline $\begin{array}{c}\text { Could you please tell if } \\
\text { project based learning is } \\
\text { incorporated into WTE } \\
\text { curriculum? }\end{array}$ & $\begin{array}{c}\text { I can't say precisely but I know projects are part of } \\
\text { the curriculum that students must present before } \\
\text { graduation (RL) }\end{array}$ & Project work \\
& No, but projects are included in the curriculum (RC) & P1
\end{tabular}

Could u please list components of PoBL suitable for integration into WTE curriculum? learning technology tools, independent learning, creativity, project presentation, asking questions, revision of work, Curriculum standards (RL) Group work presentation, collaboration, artefacts, Content standard, student ownership, authenticity, exploration activities, Investigation (RC)

Do you think it is relevant integrating PoBL components into WTE curriculum?
Yes, it is, because it will help prepare WTE students for the $21^{\text {st }}$ century work skill needs (RL) Of course yes, because if it is incorporated into WTE curriculum students' soft skill will be improved and they will not have problem of skill shortage after graduation $(\mathrm{RC})$

\footnotetext{
How can PoBL enhance students' skill if integrated into WTE curriculum?
}

\footnotetext{
Through the provision of an enabling teaching and learning environment with adequate resource materials for students' research and learning. Also by engaging students in activities that will involve investigations and Collaboration (RL) Well, I think, if implemented by lecturers, it will help enhance students' skill, and also adequate facilities like Computers and internet for research purposes if put in place will help students acquire necessary skills. Students should also be

group in PoBL class because this will help enhance their interpersonal and leadership skill (RC)
}

\author{
-Significant content \\ -Driving question \\ -Need to know \\ -Inquiry and innovation \\ -Voice and choice \\ $-21^{\text {st }}$ century skills \\ -Feedback and revision \\ -Public product presentation \\ $\mathrm{C} 1, \mathrm{C} 2, \mathrm{C} 3$, \\ C4, C5, C6, \\ $\mathrm{C} 7, \mathrm{C} 8$
}

Relevance of PoBL in WTE

P3 curriculum

Enhancement of students' skill

P4 
Findings from the interview conducted with WTE stakeholders revealed their perceptions on the questions posed to them. As presented in table 2, themes generated from the interview on the question asked about PoBL if integrated into WTE curriculum. Responses from the respondents as illustrated in figure 1 revealed that $43 \%$ of WTE curriculum planners accepted project work as part of WTE curriculum and $34 \%$ of WTE lecturers accepted as same, having $23 \%$ silence about project work as part of WTE curriculum. However, 28\% of both WTE curriculum planners and lecturers accepted PoBL as part of WTE curriculum with over $70 \%$ silent about PoBL incorporated in WTE curriculum. This indicated that PoBL is not incorporated into WTE curriculum.

Furthermore, based on the themes generated from the interview on perception of stakeholders on components of PoBL suitable for integration into WTE curriculum. As shown in figure 1, significant content was perceived by $39 \%$ of WTE curriculum planners and 37\% of WTE lecturers as a component of PoBL suitable for integration into WTE curriculum, having $24 \%$ silent. Similarly, driving question was accepted by $30 \%$ of WTE curriculum planners and $41 \%$ of WTE lecturers as a component of PoBL suitable for integration into WTE curriculum with 29\% not accepting need to know as a component to be integrated into WTE curriculum. Equally, $45 \%$ of WTE curriculum planners and $38 \%$ of WTE lecturers perceived need to know as a PoBL component to be integrated into WTE curriculum while $17 \%$ do not perceive as same. Moreover, Inquiry and innovation was accepted as a component of PoBL suitable for integration into WTE curriculum based on the perception of $33 \%$ of the WTE curriculum planners and $32 \%$ of WTE lecturers. However, only about 35\% do not perceive inquiry and innovation as a component of PoBL suitable for integration into WTE curriculum. Additionally, 37\% of WTE lecturers and $32 \%$ of WTE curriculum planners accepted voice and choice as a component of PoBL suitable for integration into WTE curriculum, having $31 \%$ not accepting. Further, $21^{\text {st }}$ century skill was accepted as a component of PoBL suitable for integration into WTE curriculum by $47 \%$ WTE lecturers and $45 \%$ WTE curriculum planners, having $8 \%$ silent. Feedback and revision was accepted by $38 \%$ of curriculum planners and $36 \%$ WTE lecturers as a component of PoBL suitable for integration into WTE curriculum. 21\% were silent about feedback and revision as a component of PoBL to be included in WTE curriculum. Public product presentation was accepted by $40 \%$ of WTE lecturers and 36\% WTE curriculum planners as a component of PoBL suitable for integration into WTE curriculum having 24\% silent. However, from the overall perception of WTE curriculum planers and lecturers, significant content, driving question, need to know, Inquiry and innovation, voice and choice, $21^{\text {st }}$ century skills feedback and revision, and public product presentation were perceived as components of PoBL suitable for integration into WTE curriculum.

Moreover, Base on the perception of stakeholders when asked about relevance of PoBL components in WTE curriculum, $42 \%$ of WTE curriculum planners and $40 \%$ of WTE lecturers accepted PoBL components as relevant in the curriculum of WTE, having $18 \%$ silent. Similarly, perception of stakeholders on how PoBL enhances student skill if integrated into WTE curriculum revealed $44 \%$ of WTE curriculum planners and 35\% WTE lecturers stating engagement of students in investigation, collaboration grouping, and provision of adequate resource facilities as ways through which PoBL components can enhance student skill when integrated into WTE curriculum. 


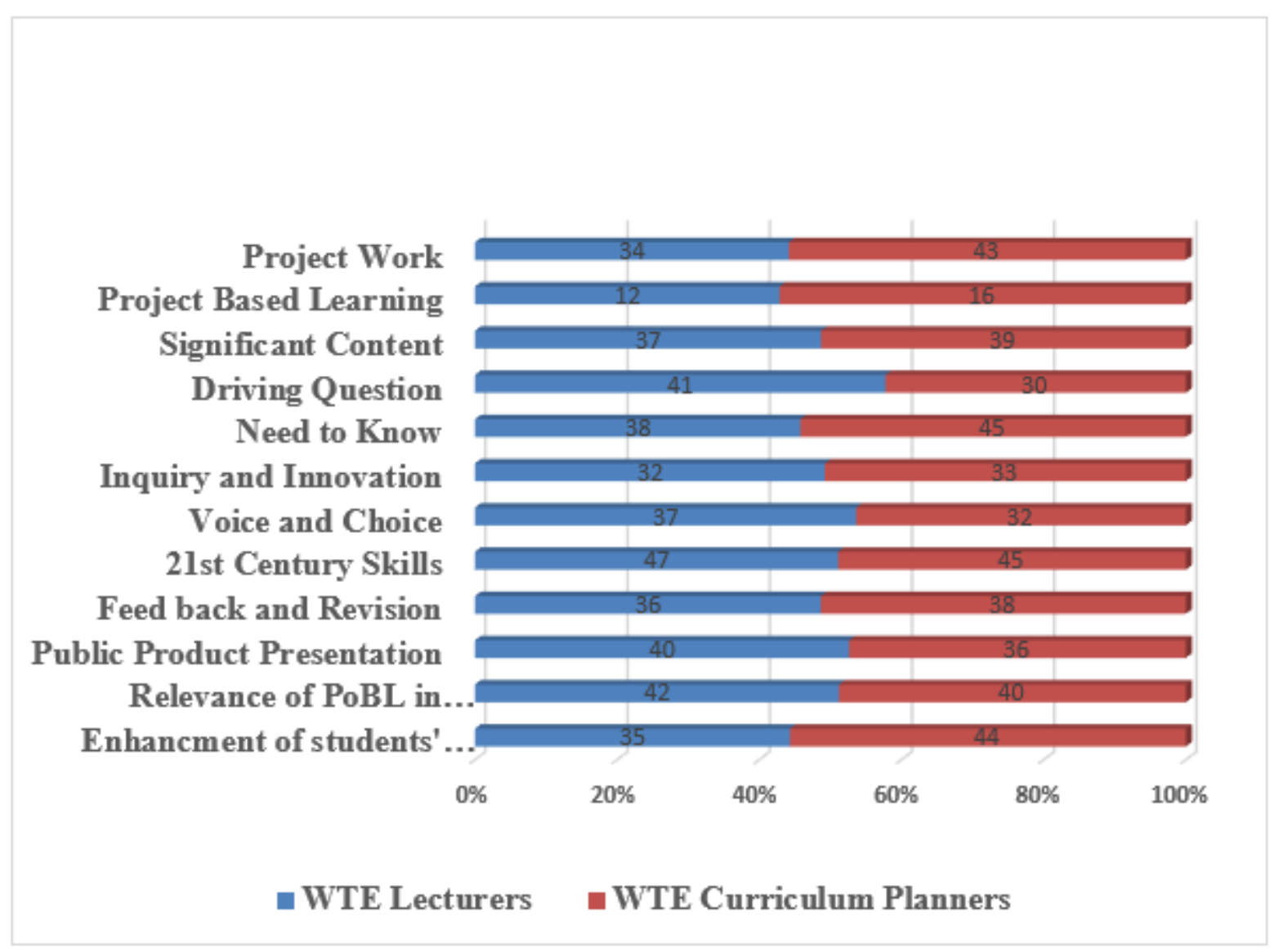

Figure 1. Chart illustrating components of PoBL Suitable for integration into WTE Curriculum

\section{Discussion}

Findings from the qualitative data revealed that PoBL has not yet been integrated into WTE curriculum, but evidently proven that project method has been incorporated into WTE curriculum as the instructional approach utilize in imparting WTE knowledge and skills to students. This is in line with the view of [24] who observed that WTE curriculum is undoubtedly challenged with the problem of an integrated instructional curricular which include lecture, demonstration and project method. He further stated that WTE curriculum still poses outdated approaches in instructional processes. Similarly, [9] remarked that, curriculum of colleges of education in Nigeria does not fully acknowledge the new age environment in schools and classrooms in terms of constructivist learning, learner-centred instructions and integrating them into the curriculum and instructional processes. Additionally, the [7] in the revised minimum standard curriculum for VTE explicitly stipulated that the method of instruction to be utilise for WTE shall be lecture, tutorial and project work.

Furthermore, based on the findings on significant content as a component of PoBL to be included in WTE curriculum, it was accepted by $76 \%$ of the respondents despite silence by $24 \%$. This implies that significant content is a component of PoBL to be included in WTE curriculum. [3] buttressed this finding because they included significant content as a component of PoBL for curriculum of an educational program. In a similar vein, findings on driving question showed $71 \%$ acceptance from participants in spite non acceptance from $29 \%$ of the participants. it could be accepted as a component of PoBL suitable for integration into WTE curriculum because [17] posited that driving question is a key component in PoBL which guides students in their part of inquiry in exploration of intriguing investigations. Further, $83 \%$ of participants identified need to know as a component of WTE suitable for integration into WTE curriculum. This indicated that need to know is a component of PoBL suitable for integration into WTE curriculum though $17 \%$ were silent. This is in accordance with the view of [16] who asserted that need to know is a component of PoBL aimed towards directing student to comprehend the significance of knowledge, understanding concepts and application of skills for problem solving and developing projects. Moreover, findings on inquiry and innovation, revealed $67 \%$ of the participants' acceptance as a component of PoBL suitable for integration into WTE curriculum despite $33 \%$ non-accepting. In this regard, Inquiry and innovation is a component of PoBL suitable for integration into WTE curriculum. This finding is in line with the opinion of [18] that Inquiry and innovation are key components in PoBL 
leading students to authentic innovations to derive new answer to driving question, or develop a new product.

Based on the findings from the participants on voice and choice, it revealed that $69 \%$ of the participants accepted voice and choice as a component of PoBL suitable for integration into WTE curriculum. Despite $31 \%$ silence, voice and choice is still accepted as a component of PoBL suitable for integration into WTE curriculum. This finding was further buttressed by Kolmos [19] who mentioned voice and choice as PoBL component needed for successful teaching and learning which allow students to decide on the content of their learning. $21^{\text {st }}$ century skill was perceived by $92 \% \%$ of the participants as a PoBL component suitable for integration into WTE program. $21^{\text {st }}$ century skill could be accepted as a component of PoBL suitable for WTE curriculum although 8\% participants' silence. This finding is in accordance with the opinion of Harris [21] who listed $21^{\text {st }}$ century as a component of PoBL with a set of abilities that students need to develop in order to succeed in global economy. Findings on feedback and revision showed $74 \%$ of the participants accepting it as a component of PoBL suitable for integration into WTE curriculum even though $26 \%$ were silent, it is accepted as a component of PoBL suitable for integration in WTE curriculum. In support of this finding, [18] identified feedback and revision as a component of PoBL which enhances ability of students to evaluate their work leading them to revise or conduct further inquiry. Findings on public product presentation revealed $76 \%$ of participants accepted it as component of PoBL suitable for integration into WTE curriculum. Public product presentation could be considered suitable for WTE curriculum notwithstanding $24 \%$ participants' silence. This finding is in line with the view of [14] that public product presentation is a component of PoBL which showcase students' product to classmates or outside audience which the project impacts.

Based on the findings on relevance of PoBL components in WTE, $82 \%$ of the participants accepted that PoBL components will have relevance if integrated into WTE curriculum. This finding is in accordance with the view of [15] that integration of PoBL components have much relevance in school instructions especially when integrated into a curriculum that emphasizes skill acquisition. They further stated that including PoBL components in a school curriculum engage students in creative and innovative experiences with the possibility for enhancing student's $21^{\mathrm{st}}$ century skills. Furthermore, perception of stakeholders on how PoBL enhances student skill if integrated into WTE curriculum revealed $79 \%$ of participants stating engagement of students in investigation, collaboration grouping, and provision of adequate resource facilities as ways through which PoBL components can enhance student skill when integrated into WTE curriculum. This finding is in line with [11] who advocated for provision of necessary materials for PoBL implementation in educational institutions as crucial for promoting students' thinking and learning and help them to be responsible for their own learning. Accordingly, [35] stated that working in group is key factor for a project to be considered PoBL. He (Bender) further lamented that when students work in collaboration group in PoBL they learn social interaction with their pears and also their capacity and learning through shared cognition increases.

\section{Conclusions}

Integrating PoBL components is crucial in the curriculum of an educational program that emphasizes skill acquisition like WTE. PoBL components serve as driving agents for a successful PoBL implementation. Therefore, integrating these components of PoBL into WTE curriculum guarantees a platform for enhancement of student's skill, and as well close the skill gap existing between WTE graduates and the industries. Findings from this study has shown that PoBL has not yet been incorporated into WTE curriculum in Nigerian colleges of education. It was also identified from the Findings in this study that an integration of the eight essential components of PoBL is desirable in WTE curriculum. To this end, the study recommends that the Nigerian government should as a matter of urgency restructure WTE curriculum at COE through incorporation of $\mathrm{PoBL}$ components into the curriculum and ensure the provision of necessary facilities needed for the implementation of PoBL so as to achieve the overall aims and objective of WTE in Nigerian colleges of education.

\section{REFERENCES}

[1] Efstratia, D. (2014). Experiential education through project based learning. Procedia-Social and Behavioral Sciences, 152, 1256-1260.

[2] English, M. C., \& Kitsantas, A. (2013). Supporting student self-regulated learning in problem-and project-based learning. Interdisciplinary Journal of Problem-Based Learning, 7(2), 6.

[3] Larmer, J., \& Mergendoller, J. R. (2010).Essentials for project-based learning. Educational leadership, 68(1), 34-37.

[4] Aliyu, A. M. (2016). Strategies for Improving Practical Projects in Woodwork in Colleges of Education (Technical) in North-Western States of Nigeria.

[5] Hassan, A. M. (2017). Effects of Challenge-Based and Activity-Based Learning Approaches on Technical Colleges Students' Achievement, Interest and Retention in Woodwork Technology

[6] Kennedy, G. W., Udoetuk, U. S., \& Ufot, S. I. (2017). Challenges of Technical Vocational Teacher Education and Teaching in Nigeria: The Need for Intervention. 
International Journal of Education and Evaluation, 3(7).

[7] Federal Republic of Nigeria (2012). Nigeria certificate in education minimum standard for vocational and Technical education (Revised .ed) Tertiary education trust fund.

[8] Federal Republic of Nigeria (2013). National Policy on Education (Revised.ed). Abuja: National Education Research and Development Council Press

[9] Adeosun, O. (2014). Teacher education programmes and the acquisition of 21 st century skills: Issues and challenges in Nigeria. Retrieved 14th March.

[10] Isa, M. U., \& Kamin, Y. B. (2019). Integrating Project Based Learning into Woodwork Technology Education in Nigerian Tertiary Institutions. Asia Proceedings of Social Sciences, 4(3), 59-61.

[11] Williams, D. L. (2017). The Impact of Project-Based Learning on Fourth-Grade Students' Understanding in Reading. ProQuest LLC.

[12] Partnership for 21st Century Learning (2012). Framework for 21st Century Learning. Retrieved from http://www.battelleforkids.org/networks/p21

[13] Lai, C.S. (2013). A study of computer project-based learning on electric circuits for 4th graders. The Journal of Human Resource and Adult Learning, 9(1), 55.

[14] Clark, B. A. (2017). Project based learning: assessing and measuring student participation.

[15] Larmer, J., \& Mergendoller, J. (2015). Why we changed our model of the " 8 essential elements of PBL". Buck Institute for Education.

[16] Ambika, D. (2015). Project-Based Learning in Digital Image Processing Course. Journal of Engineering Education Transformations, 280-285.

[17] Craig, T. T. (2015). A statistical analysis of the effects of project-based learning on student high school and college outcomes.

[18] Cervantes, B. M. (2014). The impact of project-based learning on mathematics and reading achievement of 7 th and 8th grade students in a south Texas school district.

[19] Kolmos, A., \& de Graff, E. (2014). Problem-based and project-based learning in engineering education. Cambridge handbook of engineering education research, 141-161.

[20] Kolmos, A. (2012). Changing the curriculum to problem-based and project-based learning. In outcome-based science, technology, engineering, and mathematics education: innovative practices (pp. 50-61): IGI global.

[21] Harris, M. J. (2015). The challenges of implementing project-based learning in middle schools. University of Pittsburgh,

[22] Markham, T. (2011). Project based learning a bridge just far enough. Teacher librarian, 39(2), 38.

[23] Reeve, E. M. (2016). 21st century skills needed by students in technical and vocational education and training (TVET). Asian International Journal of Social Sciences, 16(4),
$65-82$.

[24] Matthews, J. (2017). The role of a local newspaper after disaster: an intrinsic case study of Ishinomaki, Japan. Asian Journal of Communication, 27(5), 464-479.

[25] Hancock, D. R., \& Algozzine, B. (2016). Doing case study research: A practical guide for beginning researchers: Teachers College Press.

[26] Yazan, B. (2015). Three approaches to case study methods in education: Yin, Merriam, and Stake. The Qualitative Report, 20(2), 134-152.

[27] Shuaibu, H., \& Kamin, Y. B. (2019). Need Analysis for Infusing Entrepreneurship Skills into Radio, Television and Electronic Work Programme in Technical Colleges in North-Western Nigeria. Asia Proceedings of Social Sciences, 4(3), 40-44.

[28] Collins, K. M., Onwuegbuzie, A. J., \& Jiao, Q. G. (2007). A mixed methods investigation of mixed methods sampling designs in social and health science research. Journal of Mixed Methods Research, 1(3), 267-294

[29] Etikan, I., Musa, S. A., \& Alkassim, R. S. (2016). Comparison of convenience sampling and purposive sampling. American journal of theoretical and applied statistics, 5(1), 1-4.

[30] Rabionet, S. E. (2011). How I Learned to Design and Conduct Semi-Structured Interviews: An Ongoing and Continuous Journey. Qualitative Report, 16(2), 563-566.

[31] Adeosun, O. (2014). Teacher education programmes and the acquisition of 21 st century skills: Issues and challenges in Nigeria. Retrieved 14th March.

[32] Isa, M. U., \& Kamin, Y. B. (2019). Integrating Project Based Learning into Woodwork Technology Education in Nigerian Tertiary Institutions. Asia Proceedings of Social Sciences, 4(3), 59-61.

[33] Williams, D. L. (2017). The Impact of Project-Based Learning on Fourth-Grade Students' Understanding in Reading. ProQuest LLC.

[34] Partnership for 21st Century Learning (2012). Framework for 21st Century Learning. Retrieved from http://www.battelleforkids.org/networks/p21

[35] Lai, C.S. (2013). A study of computer project-based learning on electric circuits for 4 th graders. The Journal of Human Resource and Adult Learning, 9(1), 55.

[36] Clark, B. A. (2017). Project based learning: assessing and measuring student participation.

[37] Larmer, J., \& Mergendoller, J. (2015). Why we changed our model of the " 8 essential elements of PBL". Buck Institute for Education.

[38] Ambika, D. (2015). Project-Based Learning in Digital Image Processing Course. Journal of Engineering Education Transformations, 280-285.

[39] Craig, T. T. (2015). A statistical analysis of the effects of project-based learning on student high school and college outcomes.

[40] Cervantes, B. M. (2014). The impact of project-based 
learning on mathematics and reading achievement of 7 th and 8th grade students in a south Texas school district.

[41] Kolmos, A., \& de Graff, E. (2014). Problem-based and project-based learning in engineering education. Cambridge handbook of engineering education research, 141-161.

[42] Kolmos, A. (2012). Changing the curriculum to problem-based and project-based learning. In outcome-based science, technology, engineering, and mathematics education: innovative practices (pp. 50-61): IGI global.

[43] Harris, M. J. (2015). The challenges of implementing project-based learning in middle schools. University of Pittsburgh,

[44] Markham, T. (2011). Project based learning a bridge just far enough. Teacher librarian, 39(2), 38.

[45] Reeve, E. M. (2016). 21st century skills needed by students in technical and vocational education and training (TVET). Asian International Journal of Social Sciences, 16(4), 65-82.

[46] Matthews, J. (2017). The role of a local newspaper after disaster: an intrinsic case study of Ishinomaki, Japan. Asian Journal of Communication, 27(5), 464-479.

[47] Hancock, D. R., \& Algozzine, B. (2016). Doing case study research: A practical guide for beginning researchers: Teachers College Press.

[48] Yazan, B. (2015). Three approaches to case study methods in education: Yin, Merriam, and Stake. The Qualitative Report, 20(2), 134-152.

[49] Shuaibu, H., \& Kamin, Y. B. (2019). Need Analysis for Infusing Entrepreneurship Skills into Radio, Television and Electronic Work Programme in Technical Colleges in North-Western Nigeria. Asia Proceedings of Social Sciences, 4(3), 40-44.

[50] Collins, K. M., Onwuegbuzie, A. J., \& Jiao, Q. G. (2007). A mixed methods investigation of mixed methods sampling designs in social and health science research. Journal of Mixed Methods Research, 1(3), 267-294

[51] Etikan, I., Musa, S. A., \& Alkassim, R. S. (2016). Comparison of convenience sampling and purposive sampling. American journal of theoretical and applied statistics, 5(1), 1-4.

[52] Rabionet, S. E. (2011). How I Learned to Design and Conduct Semi-Structured Interviews: An Ongoing and Continuous Journey. Qualitative Report, 16(2), 563-566.

[53] Sproule, C. F. (2009). Rationale and research evidence supporting the use of content validation in personnel assessment. International Personnel Assessment Council monograph.Diterimadari:http://www.ipacweb.org/Resourc es/Documents/monographs/monograph_0901_sproule.pdf

[54] Creswell, J. W. (2014). A concise introduction to mixed methods research: Sage Publications.

[55] Given, L. M. (2008). The Sage encyclopedia of qualitative research methods: Sage publications

[56] Muhammad, I. U. (2016). Functional woodwork technology for national development. BichiJournal of education review (BIJER). 3(1),137 - 143.

[57] Bender, W. N. (2012). Project-based learning: Differentiating instruction for the 21st century: Corwin Press. 